\title{
Medicine at sea: the front line of the migrant crisis
}

$\mathrm{D}$ r. Simon Bryant was a ship doctor on an Arctic cruise when he got the call to join a very different kind of crew.

Humanitarian charity Médecins Sans Frontières (MSF) was launching the Phoenix, a search-and-rescue vessel. The mission: to provide emergency assistance to people fleeing by boat from Africa and the Middle East across the Mediterranean Sea to Europe.

Some 800000 people have made the crossing this year, often in dangerously overcrowded, unseaworthy boats. Many suffer from untreated medical conditions and injuries, and more than 3000 have died or gone missing at sea.

"It's no exaggeration to say this is a humanitarian crisis unprecedented since the end of the Second World War," says Bryant. "It's obvious to anyone just from media reports that there's a great need for humanitarian and medical aid in southern Europe [where migrants are arriving in record numbers]."

Even so, Bryant had "no realistic expectation" of what he would encounter on board the Phoenix when he set sail with MSF on May 2. "It's definitely not about simply rescuing them from dehydration, hypothermia and drowning, but sharing one's humanity, witnessing their emotional gashes and listening to their stories," he wrote in a blog post during the voyage. Now back in Canada, Bryant shared his experiences at the front line of the migrant crisis in a $C M A J$ podcast interview. Excerpts have been edited for length.

Listen to the podcast at SoundCloud.com.

What was your routine on board the Phoenix?

The rhythm of the project was three weeks at sea on the Phoenix and then a week off. Within those three weeks, we'd go to the international waters off Libya and rescue people from these inflatable dinghies or wooden boats, provide what care we could and transport them to Italy.

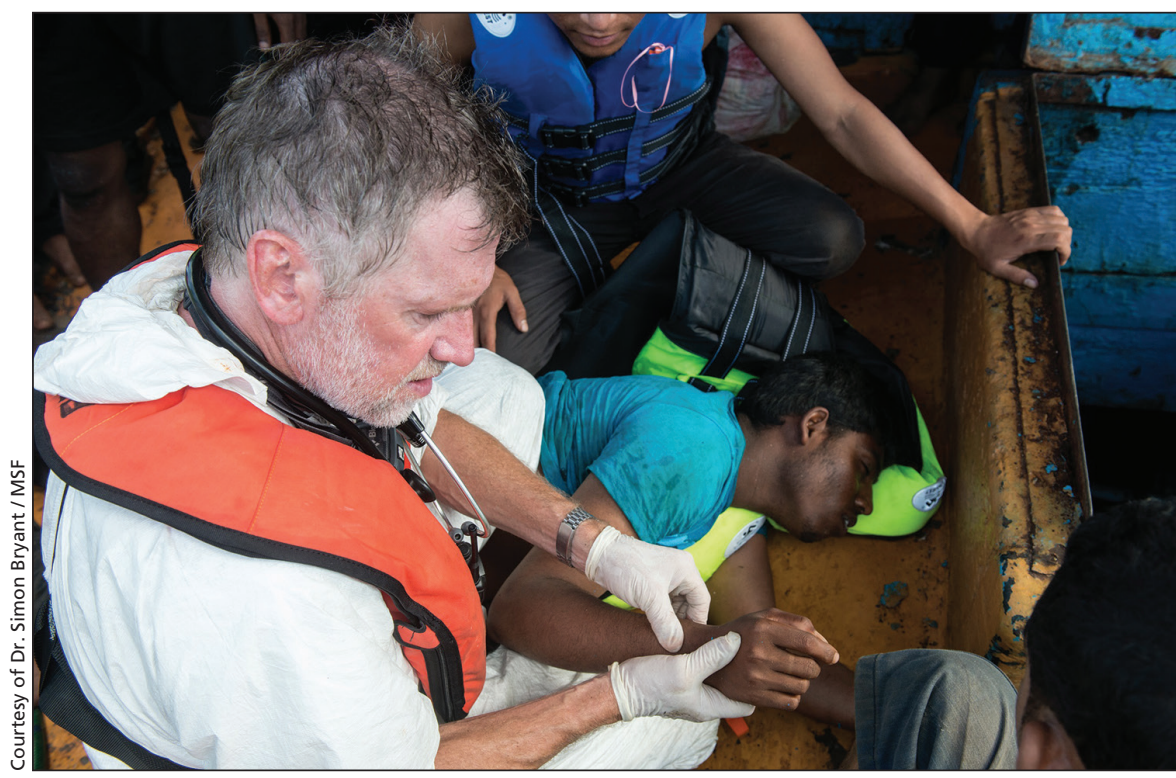

Dr. Simon Bryant of Canmore, Alberta, was involved in 27 rescues on the Mediterranean between May and September 2015.

... In the six months we were in operation, [we rescued] 6985 people, 108 [of them] less than five years of age.

\section{What kinds of medical cases did you treat?}

We did three evacuations involving helicopters from the Phoenix. We had one case of a young man with testicular torsion. Another absolutely astonishing case was a woman who had been on hemodialysis twice a week for three years in Tripoli and actually ended up on our boat not having had any treatments for three weeks. A third evacuation case was severe carbon monoxide poisoning: a gentleman that was breathing but completely unconscious onboard a wooden boat where there were 52 others dead. Those were the sort of extreme medical cases.

\section{Who are the migrants?}

They're people precisely like you and I, with the exception that they're in this situation of great personal danger. ... In one instance, we encountered a person, for example, who had worked as an MSF driver.
What don't Canadians understand about this emergency?

People, I don't think, quite understand that this is not a local Middle Eastern or European event; this is a global historic event. This is not the end of it. It's not the middle of it. It's the beginning of it. And that was brought home a couple of days ago when I saw the figure that 200000 people had made the eastern Mediterranean crossing - Turkey to Greece - in the previous month, which is more than made the crossing in all of 2014.

How did the experience change you?

At this point, I just feel like people matter more than anything else, and it's hard to draw those lines and say, "Those people are over there and we're here." You don't start thinking of people as Canadians or Eritreans or Somalians. These are just people, and those over there, in that situation, need a lot of help, and we're in a position to offer it. — Lauren Vogel, CMAJ

CMAJ 2016. DOI:10.1503/cmaj.109-5200 